\title{
OPEN Linear and nonlinear investigations for the adsorption of paracetamol and metformin from water on acid-treated clay
}

\begin{abstract}
Mohamed R. Elamin ${ }^{1,2}$, BabikerY. Abdulkhair ${ }^{1,3}$, Faisal K. Algethami ${ }^{1}$ \& L. Khezami $^{1}$
Natural clays are considered a safe, low-cost, and sound sorbent for some pharmaceutical and body care products from water. Metformin (MF) and paracetamol (PA) are of the most consumable drugs worldwide. A portion of natural clay was treated with distilled water, and another part was treated with hydrochloric acid. The water-treated clay (WTC) and the acid-treated clay (ATC) were characterized by scanning electron microscopy-energy dispersive spectroscopy, X-ray diffraction, Fourier transforms infrared spectroscopy, and nitrogen adsorption isotherm. Batch experiments were employed to investigate the influence of contact time and solution parameters on the adsorption of PA and MF on WTC and ATC. 30 min attained the equilibrium for all sorbent-sorbate systems. Both sorbents fitted the pseudo-second-order kinetic model with a preference to the nonlinear fitting, and the mechanism of adsorption partially fitted the liquid-film diffusion model. The PA and MF adsorption on WTC and ATC fitted the Freundlich model in preference to nonlinear fitting. The adsorption of pollutants on both sorbents was spontaneous, exothermic, and physisorption in nature. Even at low concentrations, both WTC and ATC showed efficiency above $80 \%$ in removing PA and MF from tab water, groundwater, and Red seawater. These findings nominated natural clay as an alternative to the costly nanomaterials as sorbents for removing pharmaceutical contaminants from water.
\end{abstract}

The presence of organic pollutants in water systems is a devastating problem facing the global environment these days. The growing demand and intensive use of Pharmaceuticals and personal care products (PPCPs) lead to the accumulation of their residues in water and wastewater systems ${ }^{1,2}$. These PPCPs may enter the water systems from humans and animals urine and feces, expired drugs discarded, washing of machinery, and discarding improperly manufactured pharmaceuticals ${ }^{3-5}$. The availability of PPCPs in water systems may cause epidemic bacteria and other microbes to gain immunity against these drugs on long exposure periods, leading to the evolution of drug resisting microbes, and finally, treatment failure ${ }^{6,7}$. Different illumination practices were encountered to remove the PPCPs residues from wastewater, including oxidation, coagulation-precipitation, reverse osmosis, electro-dialysis, and ion exchange ${ }^{8-11}$. The high cost of these processes and the need for continuous monitoring are considered among the main disadvantages of these technologies ${ }^{12}$. Adsorption is a simple procedure that can be carried out with low-cost sorbents like carbonaceous materials or natural clay minerals ${ }^{13-20}$. Although carbon materials have a large surface area, clay materials can be free because they are found naturally. Among all known adsorbents used in water treatment, clay is the cheapest and safest to the degree that it can be used as excipients or active substances in many pharmaceutical products ${ }^{21-29}$. Metformin (MF) and paracetamol (PA) are among the most consumable drugs worldwide ${ }^{30-32}$. PA was one of the eighteen PPCPs found in a Shallow lake-China, while both MF and PA were of the thirteen PPCPs found in the red-sea water ${ }^{33,34}$. In addition, PA consumption is expected to increase enormously as it had been recommended to treat the symptoms of the COVID-19 pandemic ${ }^{35-39}$. Natural clay is a safe and low-cost material, making it a suitable alternative to nano-sorbents if it has an adequate adsorption capacity. a natural clay NC was collected from the Eldoushain area, Nile river state, Sudan $\left(16^{\circ} 45^{\prime} 43.1^{\prime \prime} \mathrm{N} 33^{\circ} 35^{\prime} 25.0^{\prime \prime} \mathrm{E}\right)^{40-43}$. To improve the adsorption capacity, water treated clay (WTC) and an acid-treated clay ATC were employed for the removal of MF and PA from real water samples. Since some recent

${ }^{1}$ College of Science, Chemistry Department, Imam Mohammad Ibn Saud Islamic University (IMSIU), P.O. Box 90905, Riyadh 11623, Kingdom of Saudi Arabia. ${ }^{2}$ Industrial Research and Consultancy Center (IRCC), Khartoum North, Sudan. ${ }^{3}$ College of Science, Chemistry Department, Sudan University of Science and Technology (SUST), Khartoum, Sudan. ${ }^{\circledR}$ email: babiker35.by@gmail.com 


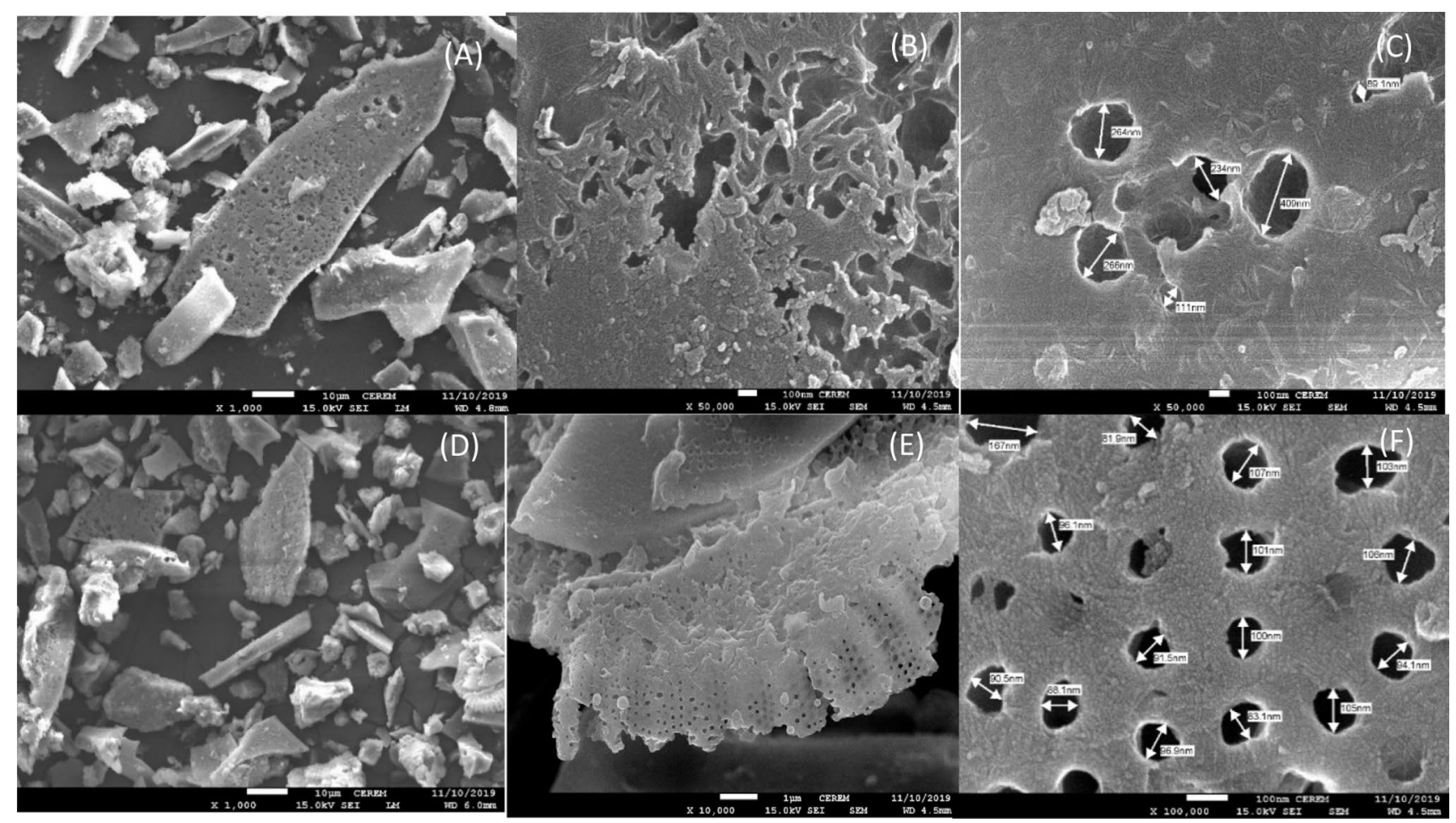

Figure 1. SEM images of the clay WTC (a-c), ATC (d-f).

papers have recommended the employment of nonlinear fitting, herein, in this study both the linear and the nonlinear fittings were employed to determine the best on a statistical basis ${ }^{44-49}$.

\section{Results and discussion}

Characterization of WTC and ATC. The surface topography of WTC and ATC was scanned with SEM. The low magnification of the WTC shows flakes with some cavities on their surface as monitored in Fig. 1a. The medium magnification revealed the irregular shape and size of the cavities which may be due to debris and mineral crystals (Fig. 1b). High magnification revealed a surface coated with fine nano granules with pores of 89-409 nm diameters (Fig. 1c). For the ATC sample, although the low magnification reflected no difference for the acid treatment (Fig. 1d), the medium magnification showed an efficient removal of debris-cover revealing a diatomaceous structure (Fig. 1e). Figure $1 \mathrm{f}$ illustrated relatively regular pores with a $100 \mathrm{~nm}$ average diameter. The porous nature of this material imparts a high surface area and porosity, making it suitable for adsorption and filtration. These results are consistent with that previously reported ${ }^{50-52}$. The elemental analysis of WTC and ATC was carried out using EDS. For WTC the content of silicon, aluminum, sodium, and potassium was $64.4 \%, 8.96 \%, 3.25 \%$, and $1.92 \%$, respectively; while ATC appeared to contain $72.5 \%, 9.12 \%, 2.56 \%$, and $1.73 \%$, respectively. These results confirmed that a considerable portion of the samples is of diatomaceous earth composition $\left(\mathrm{SiO}_{2}\right)$. The sodium, potassium, and iron were found in both samples, although the contents are a little bit lower in the ATC due to the acid treatment. Figure 2a, b demonstrates the XRD patterns of WTC and ATC, respectively. The main diffraction peaks, in both sorbents, are the diffraction peaks of $\mathrm{SiO}_{2}$, confirming the existence of diatomaceous earth mainly located in the $2 \theta$ range of $20^{\circ}-40^{\circ}$. The diffraction peaks with $2 \theta$ values of 21.0, 35.4 for WTC and 20.8 and 34.8 for ATC, can be assigned to (101) and (112) crystal faces of $\mathrm{SiO}_{2}$ (JCPDS Card No. 82-0512). In the pattern of WTC, the peaks at $2 \theta$ of $8.0,10.4,12.3,26.7,27.82,35.4,37.3,50.1$, and 54.3 are assigned to the various types of clay minerals. The ATC pattern showed peaks at $2 \theta$ of $5.17,9.83,19.7$, $20.8,26.72,27.8,25.5,34.8,36.35 .39 .45,43.5 .50 .1,58.37$, and 68 . These results were similar to the results previously reported ${ }^{27}$. The FTIR spectra for WTC and ATC are shown in Fig. 2c, d, respectively. The WTC showed six peaks at $461.7 \mathrm{~cm}^{-1}(\mathrm{~s})$, assigned to $\mathrm{Si}-\mathrm{O}-\mathrm{Si}$ bending vibrations, $793.7 \mathrm{~cm}^{-1}$, for Si-O-Al vibrations, $1022 \mathrm{~cm}^{-1}$ (s) for Si-O stretching, indicating the existence of montmorillonite clay. The peaks at $1645 \mathrm{~cm}^{-1}$ and $3412 \mathrm{~cm}^{-1}$ are assigned to bending and stretching vibrations of the combined water, respectively. The peak at $3660 \mathrm{~cm}^{-1}$ can be attributed to the stretching vibrations of the $\mathrm{Si}-\mathrm{Si}-\mathrm{OH}$ and/or $\mathrm{Si}-\mathrm{Al}-\mathrm{OH}$. The vibration bands for ATC are similar to those of WTC with slight differences in the absorption of some bands, appearing at 461.7, 793.7, 1022 (s), 1666, 3453, and $3640 \mathrm{~cm}^{-1}$. The spectra of FTIR for WTC and ATC were found to be similar to those previously reported for clays $\mathrm{s}^{50,52}$.

BET surface area of the sorbents was determined; for instance, Fig. 2e, f showed the evolution of $\mathrm{N}_{2}$ adsorption-desorption isotherms for WTC and ATC, respectively. Both WTC and ATC exhibited a sorption isotherm of type IV(a), with a hysteresis of $\mathrm{H} 4$ type $^{53}$. Such hysteresis type is an indicator of narrow slit-like pores, particles with internal voids of irregular shape and broad size distribution, hollow spheres with walls composed of ordered mesoporous particles. At elevated relative pressure $P / P^{\circ}$, the hysteresis of $\mathrm{H} 4$ type was due to the filling 

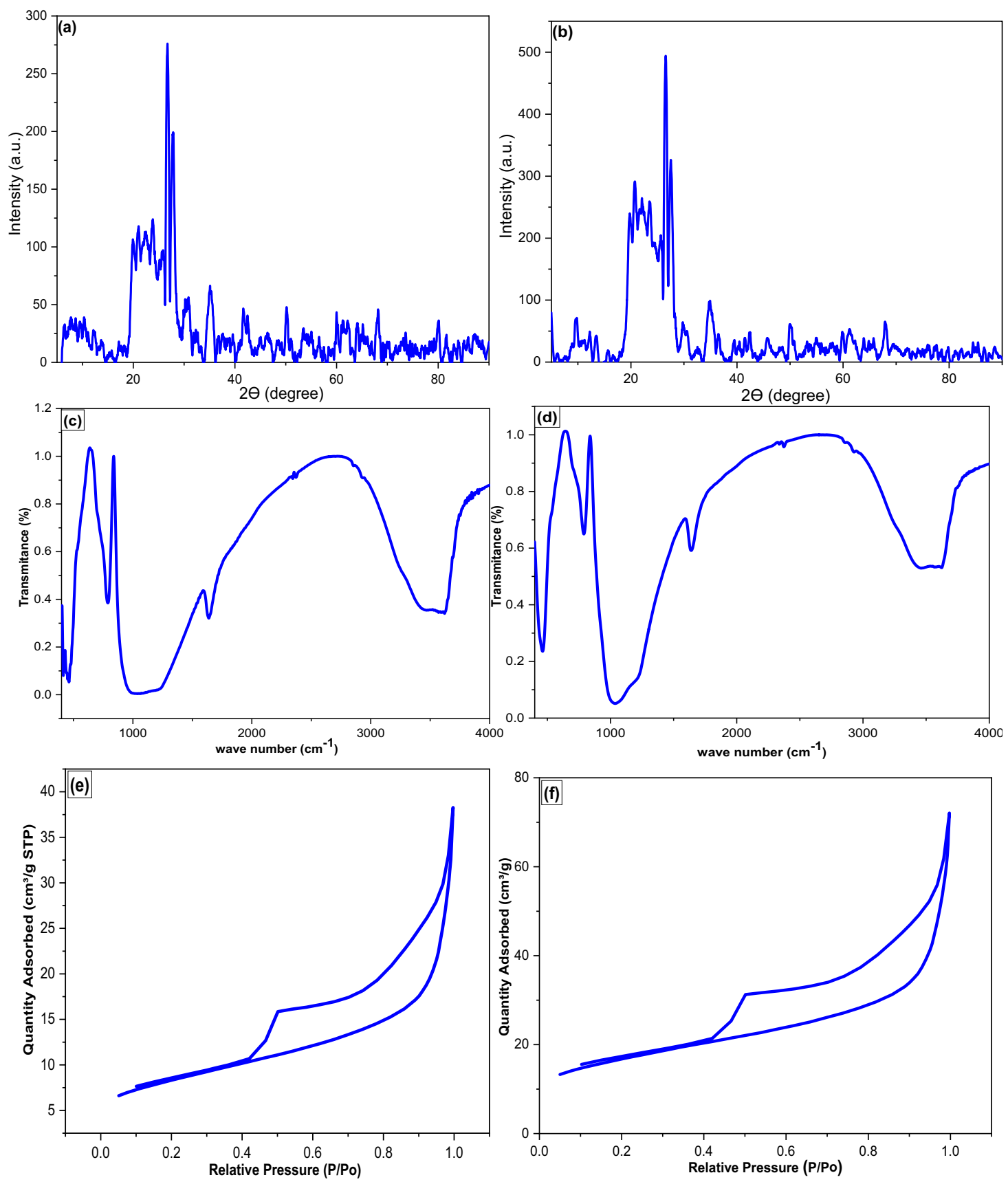

Figure 2. (a,b) XRD pattern of WTC and ATC, respectively; (c,d) are the FTIR results of WTC and ATC, respectively; (e,f) are the N2 adsorption-desorption isotherms results of WTC and ATC, respectively.

up of mesopores by capillary condensation, indicating a shape of pores that was flatter instead of cylindrical. The Surface area of WTC and ATC was 9.53 and $11.49 \mathrm{~m}^{2} \mathrm{~g}^{-1}$, respectively. The pore diameter for WTC and ATC was determined by the $\mathrm{BJH}$ method; the average diameter of pores decreased from 8.64 to $8.39 \mathrm{~nm}$. Inversely, the pore volume was increased from $2.03 \times 10^{-2}$ to $2.22 \times 10^{-2} \mathrm{~cm}^{3} \mathrm{~g}^{-1}$. These results confirmed the improvement implemented by acid treatment since the surface area increased by about $2.0 \mathrm{~m}^{2} \mathrm{~g}^{-1}$.

Adsorption studies. Adsorption of MF and PA in an aqueous solution by WTC and ATC was studied. The adsorption was possibly due to Van der Waals interactions and/or electrostatic attraction between the pharmaceutical pollutant and the sorbents ${ }^{54-56}$. The impact of WTC and ATC mass on the trend of adsorption for MF and PA was investigated. As the sorption sites increase by increasing the mass of sorbent, the adsorption percentage increased; meanwhile, the adsorption capacity decreased inversely. The efficiency of WTC and ATC in the removal of PA and MF are comparable to those found in the literature with the advantage of low cost for the sorbent in this study ${ }^{57-63}$. 
The contact time study revealed that 20 min sufficed the adsorption of MF and PA on ATC to reach the equilibrium; on the other hand, it takes $30 \mathrm{~min}$ for the adsorption of PA and MF on WTC (S. 1). The impact of ionic strength on the adsorption of PA and MF on WTC and ATC was investigated. The decrease in adsorption efficiency as the ionic strength increased may be attributed to the influence of salinity on the adsorption process (S. 2a). Also, the significant reduction in the adsorption efficiency of the MF may be attributed to the five partially negative nitrogen atoms that may repulse with any negative sites on the sorbent surface and/or negative sorbates ${ }^{64,65}$. The pH effect on the adsorption of PA and MF on WTC and ATC was investigated. The best adsorption percentage for MF on both WTC and ATC was achieved at a $\mathrm{pH}$ value of 4.0; on the other hand, the best adsorption percentage for PA on both WTC and ATC was achieved at a pH value of 6.0 (S. 2b). Moreover, the influence of initial fed concentrations of PA and MF on WTC and ATC adsorption efficiency was studied. The adsorption percentage for both sorbents was inversely proportional to the initial fed concentration for both drugs. This trend illustrates that both sorbents can be very effective for treating MF and PA at low concentrations, as expected to be in the polluted water resources.

Adsorption kinetic order. The some studies in the literature highlighted the misleading results of the linear pseudo-second-order kinetic equations ${ }^{66}$. Considering that, non-linear pseudo-first-order (NLPFO) (Eq. 1), non-linear pseudo-second-order (NLPSO) (Eq. 3), linear pseudo-first-order (LPFO) (Eq. 2), and linear pseudosecond-order (LPSO) (Eq. 4) were all employed for the kinetic study investigations ${ }^{67-69}$.

$$
\begin{gathered}
q_{t}=q_{e}\left(1-\exp ^{-K_{1 . t}}\right) \\
\ln \left(q_{e}-q_{t}\right)=\ln q_{e}-k_{1} \cdot t \\
q_{t}=\frac{k_{2} \cdot q_{e}^{2} \cdot t}{1+k_{2} \cdot q_{e} \cdot t} \\
\frac{t}{q_{t}}=\frac{1}{k_{2} \cdot q_{e}^{2}}+\frac{t}{q_{e}}
\end{gathered}
$$

where $\mathrm{k}_{1}\left(\mathrm{~min}^{-1}\right)$ is the PFO rate constant, $\mathrm{k}_{2}\left(\mathrm{~g} \mathrm{mg}^{-1} \mathrm{~min}^{-1}\right)$ is the PSO rate constant, $\mathrm{q}_{\mathrm{t}}$ and $\mathrm{q}_{\mathrm{e}}\left(\mathrm{mg} \mathrm{g}^{-1}\right)$ are the adsorbed mass of drug per unit mass of sorbent at time $t$ and equilibrium, respectively.

The adsorption rate constant were calculated from the slope of the corresponding regression ${ }^{70}$.

The adsorption kinetic orders were determined by the best linear fit judged usually by the best correlation coefficient $\left(\mathrm{R}^{2}\right)$ value ${ }^{66}$. Also, the residual sum of squares (RSS), the value of Chi-squared $\left(\chi^{2}\right)$, were considered as they reflects the goodness of regressions (Fig. 3; Table 1). The adsorption of MF and PA on WTC and ATC fitted the PSO kinetic models since it revealed the lowest $\chi^{2}$, the highest $\mathrm{R}^{2}$, a semi-typical $\mathrm{q}_{\mathrm{e}}$, and the lowest RSS value. Worthmentioning that the $\mathrm{q}_{\mathrm{e}}$ predicted from the NLPSO was almost typical to the experimental values for all sorbent-sorbate systems in this study.

Adsorption rate-controlling mechanism. The adsorption rate-control-mechanism was investigated for the adsorption of PA and MF on WTC and ATC by the employment of the intra-particle diffusion model (IPDM) (Eq. 5) and the liquid film-diffusion model (LFDM) (Eq. 6) 67,71 .

$$
q_{t}=K_{i p} * t^{\frac{1}{2}}+C_{i}
$$

where $\mathrm{k}_{\mathrm{ip}}\left(\mathrm{mg} \mathrm{g}^{-1} \mathrm{~min}^{-0.5}\right)$ is the rate constant of the IPDM. $\mathrm{C}_{\mathrm{i}}$ : concentration in $\mathrm{mg} \mathrm{g}^{-1}$ (parameter relates to the boundary layer thickness).

$$
\ln (1-F)=-K_{L F} * t
$$

where

$$
\mathrm{F}=\mathrm{q}_{\mathrm{e}} / \mathrm{q}_{\mathrm{t}}
$$

$\mathrm{k}_{\mathrm{LF}}\left(\mathrm{min}^{-1}\right)$ is the equilibrium fractional attainment.

Although the $\mathrm{K}_{\mathrm{IP}}$ values were much more than the $\mathrm{K}_{\mathrm{LF}}$ values indicating the preference of IPDM, it worth mentioning that the high $\mathrm{C}_{\mathrm{i}}$ values indicated a high boundary-layer resistance to the IPDM ${ }^{72}$. The regression results of LFDM and IPDM fittings (Fig. 4) revealed that LFDM mainly controlled the adsorption of PA and MF on WTC and ATC since it had the least RSS, the highest $\mathrm{R}^{2}$, and the least $\chi^{2}$ as demonstrated in Table 1 . Besides, the multi-linearity curve produced by IPDM evident that the adsorptions of PA and MF on WTC and ATC were complicated ones that may be controlled by two or more mechanisms ${ }^{73,74}$. This complexity may be attributed to the diverse nature of the clay sorbent; the presence of diverse types of clay minerals may impart to the difference in diffusion models.

Adsorption isotherms. The Langmuir and Freundlich isotherms were employed to investigate the adsorption of PA and MF on WTC and ATC. The linear and nonlinear forms of the Langmuir model (LLM and NLLM) were utilized to investigate the monolayer adsorption with no sorbate penetration in the surface-plane explained 

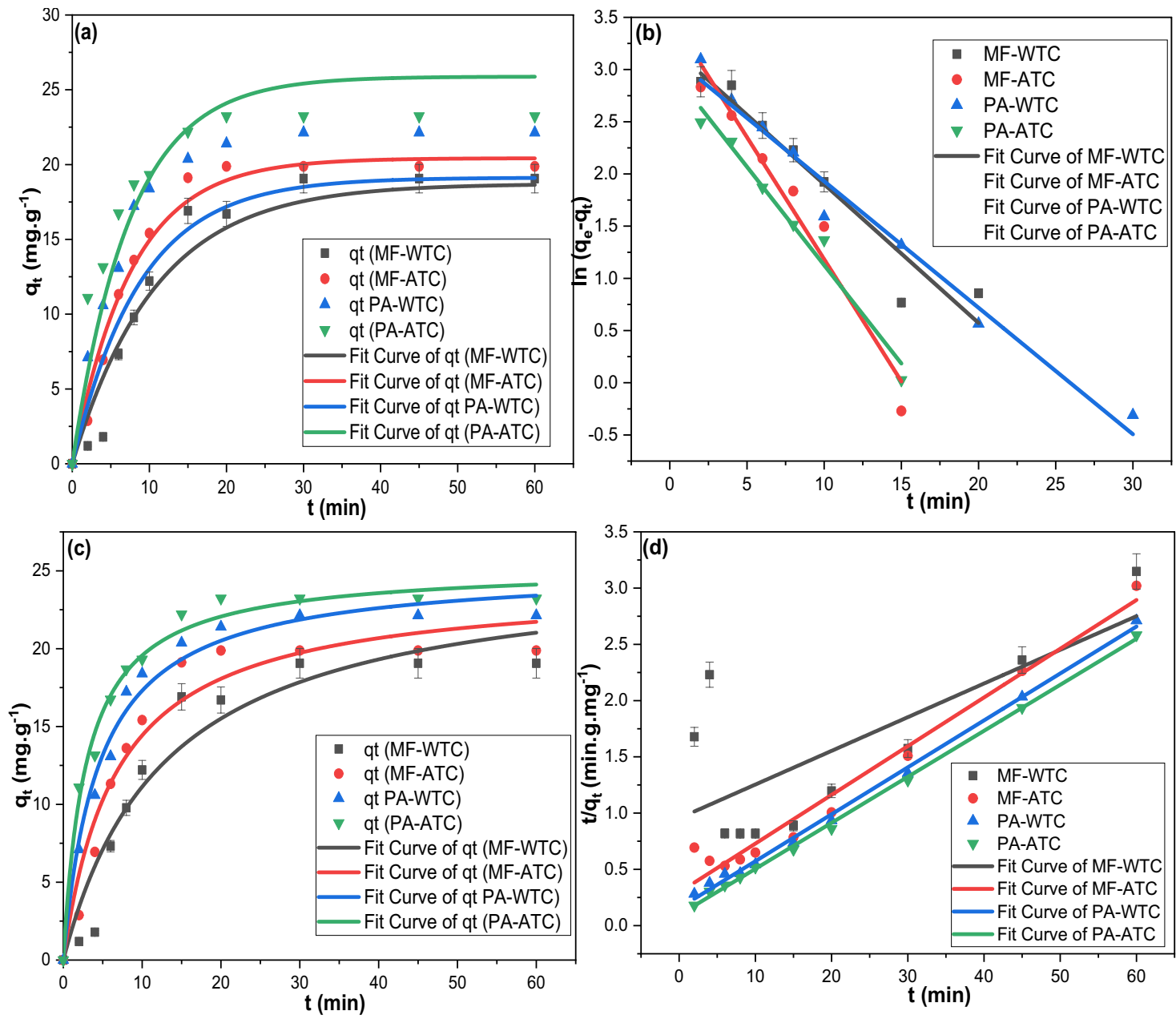

Figure 3. (a) NLPFO, (b) LPFO, (c) NLPSO, and (d) LPSO fittings for the adsorption of MF and PA on WTC and ATC.

by Eqs. (7) and (8), respectively. The adsorption nature was further investigated by the Langmuir isotherm separation factor $\left(\mathrm{S}_{\mathrm{L}}\right)$ (Eq. 9).

$$
\begin{aligned}
\frac{C_{e}}{q_{e}} & =\frac{1}{K_{L} \cdot q_{m}}+\frac{C_{e}}{q_{m}} \\
q_{e} & =\left(\frac{K_{l} q_{m} C_{e}}{1+q_{m} C_{e}}\right) \\
S_{L} & =\frac{1}{1+K_{L} \cdot C_{o}}
\end{aligned}
$$

where $\mathrm{C}_{\mathrm{e}}$ is the drug concentration at equilibrium, $\mathrm{q}_{\mathrm{m}}$ and $\mathrm{K}_{\mathrm{L}}\left(\mathrm{L} \mathrm{mg}^{-1}\right)$ represent the maximum adsorption capacity, and the Langmuir constant corresponds to the monolayer adsorption, respectively. As a multilayered adsorption model, the linear and the nonlinear forms of the Freundlich model (LFM and NLFM) were employed in this study (Eqs. 10, 11, respectively).

$$
\begin{gathered}
\ln q_{e}=\ln K_{F}+\frac{1}{n} \ln c_{e} \\
q_{e}=K_{F} \cdot C_{e}^{1 / n}
\end{gathered}
$$

$K_{F}\left(\mathrm{~L} \mathrm{~g}^{-1}\right)$ is the Freundlich constant, while $\boldsymbol{n}$ (arbitrary) is the Freundlich heterogeneity factor related to the adsorption capacity. Worth mentioning that an $\mathrm{n}$ value ranged between 0 and 10 indicates the favourability adsorption process ${ }^{75}$. Figure 5 illustrated the fitted curves of isotherms while the obtained isotherms parameters were monitored in Table 1. The adsorption of PA and MF on WTC and ATC does not fit the LLM or NLLM. 


\begin{tabular}{|c|c|c|c|c|c|c|c|c|c|c|}
\hline Parameter $\downarrow$ & Sorbent-sorbate & LPFO & NLPFO & LPSO & NLPSO & \begin{tabular}{|l} 
Sorbent- \\
sorbate
\end{tabular} & LPFO & NLPFO & LPSO & NLPSO \\
\hline \multicolumn{11}{|c|}{ Adsorption kinetic models } \\
\hline $\mathrm{q}_{\mathrm{e}}$ exp. $\left(\mathrm{mg} \mathrm{g}^{-1}\right)$ & \multirow{6}{*}{ WTC-MF } & \multicolumn{4}{|l|}{19.061} & \multirow{6}{*}{ ATC-MF } & \multicolumn{4}{|l|}{22.133} \\
\hline $\mathrm{q}_{\mathrm{e}} \mathrm{cal} .(\mathrm{mg} / \mathrm{g})$ & & 25.268 & 18.719 & 33.411 & 25.582 & & 33.788 & 20.426 & 23.095 & 24.167 \\
\hline Rate constant & & 0.133 & 0.093 & 0.001 & 0.003 & & 0.234 & 0.131 & 0.006 & 0.006 \\
\hline $\mathrm{R}^{2}$ & & 0.927 & 0.939 & 0.515 & 0.927 & & 0.957 & 0.984 & 0.971 & 0.951 \\
\hline$X^{2}$ & & 0.019 & 3.524 & 0.355 & 4.688 & & \begin{tabular}{|l|}
0.059 \\
\end{tabular} & 0.962 & 0.024 & 2.928 \\
\hline RSS & & 0.336 & 31.715 & 2.838 & 42.189 & & 0.264 & 8.656 & 0.192 & 26.353 \\
\hline $\mathrm{q}_{\mathrm{e}} \exp \cdot(\mathrm{mg} / \mathrm{g})$ & \multirow{6}{*}{ WTC-PA } & \multicolumn{4}{|l|}{19.879} & \multirow{6}{*}{ ATC-PA } & \multicolumn{4}{|l|}{23.233} \\
\hline $\mathrm{q}_{\mathrm{e}}$ cal. (mg/g) & & 23.136 & 19.127 & 23.969 & 25.186 & & \begin{tabular}{|l|}
20.289 \\
\end{tabular} & 25.880 & 24.450 & 30.523 \\
\hline Rate constant & & 0.121 & 0.114 & 0.011 & 0.009 & & 0.188 & 0.134 & 0.017 & 0.005 \\
\hline $\mathrm{R}^{2}$ & & 0.977 & 0.936 & 0.997 & 0.982 & & \begin{tabular}{|l|}
0.973 \\
\end{tabular} & 0.967 & 0.998 & 0.988 \\
\hline$X^{2}$ & & 0.046 & 3.890 & 0.002 & 1.110 & & 0.110 & 3.231 & 0.001 & 0.722 \\
\hline RSS & & 0.215 & 35.009 & 0.020 & 9.989 & & 0.105 & 29.082 & 0.009 & 6.500 \\
\hline \multirow[b]{2}{*}{ Sorbate -sorbent $\downarrow$} & \multicolumn{5}{|l|}{ IPDM } & \multicolumn{5}{|l|}{ LFDM } \\
\hline & $K_{I P}\left(m g \cdot g^{-1} \min ^{1 / 2}\right)$ & $\mathrm{C}\left(\mathrm{mg} \cdot \mathrm{g}^{-1}\right)$ & $R^{2}$ & $\mathbf{X}^{2}$ & RSS & $\begin{array}{l}\mathrm{K}_{\mathrm{LF}} \\
(\mathrm{min}-1)\end{array}$ & $\mathbf{R}^{2}$ & $\mathrm{X}^{2}$ & RSS & \\
\hline \multicolumn{11}{|c|}{ Adsorption rate-control mechanism models } \\
\hline MF-WTC & 2.968 & 0.398 & 0.775 & 12.448 & 99.585 & 0.133 & 0.927 & 0.067 & 0.336 & \\
\hline MF-ATC & 2.437 & 5.101 & 0.682 & 13.498 & 107.987 & 0.234 & 0.957 & 0.066 & 0.264 & \\
\hline PA-WTC & 2.192 & 8.660 & 0.708 & 9.629 & 77.034 & 0.170 & 0.994 & 0.009 & 0.045 & \\
\hline \multirow[t]{2}{*}{ PA-ATC } & 1.819 & 12.115 & 0.707 & 6.664 & 53.312 & 0.188 & 0.973 & 0.026 & 0.105 & \\
\hline & MF-WTC & MF-WTC & PA-WTC & PA-ATC & MF-WTC & MF-WTC & PA-WTC & PA-ATC & & \\
\hline \multicolumn{11}{|c|}{ Adsorption Isotherms parameters } \\
\hline & \multicolumn{4}{|l|}{ LLM } & \multicolumn{4}{|l|}{ NLLM } & & \\
\hline $\mathrm{q}_{\mathrm{m}}\left(\mathrm{mg} \mathrm{g}^{-1}\right)$ & 31.827 & 37.453 & 43.917 & 25.240 & 36.343 & 29.357 & 46.110 & 32.673 & & \\
\hline $\mathrm{K}_{\mathrm{L}}$ & 0.175 & 0.191 & 0.085 & 0.990 & 0.004 & 0.011 & 0.003 & 0.015 & & \\
\hline $\mathrm{X}^{2}$ & 0.000 & 0.001 & 0.009 & 0.000 & 0.263 & 0.454 & 0.904 & 2.277 & & \\
\hline RSS & 0.001 & 0.002 & 0.028 & 0.001 & 0.789 & 1.361 & 2.711 & 6.832 & & \\
\hline $\mathrm{R}^{2}$ & 0.969 & 0.858 & 0.314 & 0.930 & 0.995 & 0.993 & 0.987 & 0.972 & & \\
\hline $\mathrm{C}_{\mathrm{o}} \downarrow$ & \multicolumn{4}{|l|}{$\mathrm{S}_{\mathrm{L}}$ values from LLM } & \multicolumn{4}{|c|}{$\mathrm{S}_{\mathrm{L}}$ values from NLLM } & & \\
\hline 1 & 0.851 & 0.840 & 0.922 & 0.503 & 0.996 & 0.989 & 0.997 & 0.985 & & \\
\hline 5 & 0.533 & 0.512 & 0.702 & 0.168 & 0.981 & 0.949 & 0.985 & 0.931 & & \\
\hline 10 & 0.363 & 0.344 & 0.541 & 0.092 & 0.963 & 0.903 & 0.971 & 0.870 & & \\
\hline 15 & 0.275 & 0.259 & 0.440 & 0.063 & 0.946 & 0.861 & 0.958 & 0.817 & & \\
\hline \multirow[t]{2}{*}{20} & 0.222 & 0.208 & 0.370 & 0.048 & 0.929 & 0.823 & 0.944 & 0.770 & & \\
\hline & \multicolumn{4}{|l|}{ LFM } & \multicolumn{4}{|l|}{ NLFM } & & \\
\hline $\mathrm{K}_{\mathrm{F}}$ & 4.269 & 5.700 & 5.088 & 10.411 & 1.433 & 1.648 & 1.352 & 1.779 & & \\
\hline $\mathrm{n}$ & 0.799 & 0.816 & 0.860 & 0.910 & 4.793 & 6.921 & 5.752 & 10.528 & & \\
\hline $\mathrm{X}^{2}$ & 0.016 & 0.044 & 0.017 & 0.024 & 0.105 & 1.364 & 1.143 & 0.491 & & \\
\hline RSS & 0.048 & 0.131 & 0.051 & 0.073 & 0.316 & 4.092 & 3.428 & 1.473 & & \\
\hline $\mathrm{R}^{2}$ & 0.991 & 0.975 & 0.991 & 0.986 & 0.998 & 0.979 & 0.983 & 0.994 & & \\
\hline
\end{tabular}

Table 1. The kinetics and isotherms parameters for the adsorption of MF and PA on WTC and ATC.

Meanwhile, the $S_{L}$ results calculated from the $K_{L}$ generated by both models reflected the favorable nature of the adsorption process $\left(S_{L} \text { values less than one }\right)^{76}$. So, based on the obtained statistical parameters, the adsorption of PA and MF on WTC and ATC fitted the NLFM with the highest $\mathrm{R}^{2}$ values and the least RSS and $\chi^{2}$ values. Besides, the $\mathrm{n}$ values generated from NLFM revealed a strong adsorption bond since the $\mathrm{n}$ values ranged between 4.793 and $10.528^{77-80}$.

\section{Thermodynamic studies}

The temperature impact on the adsorptions of PA and MF on WTC and ATC was investigated, and for a better understanding of the adsorption behaviors of PA and MF on WTC and ATC, the thermodynamics of this process was investigated. The thermodynamic parameters, including the enthalpy $\left(\Delta \mathrm{H}^{\circ}\right)$, entropy $\left(\Delta \mathrm{S}^{\circ}\right)$, and Gibbs free energy $\left(\Delta G^{\circ}\right)$, were evaluated (Eqs. 12, 13). 


$$
\begin{aligned}
\ln K_{c} & =\frac{\Delta H^{o}}{R T}+\frac{\Delta S^{o}}{R} \\
\Delta G^{o} & =\Delta H^{o}-T \Delta S^{o}
\end{aligned}
$$

The $\Delta \mathrm{G}^{\mathrm{o}}, \Delta \mathrm{H}^{\mathrm{o}}$, and $\Delta \mathrm{S}^{\mathrm{o}}\left(\mathrm{kJ} \mathrm{mol}^{-1}\right)$ were calculated from the plot of $\ln \left(\mathrm{K}_{\mathrm{c}}\right)$ versus $(1 / \mathrm{T})$ as shown in Fig. 6 . The ideal gas constant $\left(\mathrm{R}=0.0081345 \mathrm{~kJ} \mathrm{~mol}^{-1}\right)$ was applied in all calculations, and the thermodynamic parameters were monitored in Table 2. The negative $\Delta \mathrm{H}^{\circ}$ values indicated the exothermic nature of the adsorption of PA and MF on both sorbents meaning that the adsorption efficiency may be enhanced by lowering the solution's temperature. Besides, a $\Delta \mathrm{H}^{\circ}$ of less than $40 \mathrm{~kJ}$ mol indicates a physisorption process; conversely, it is considered chemisorption when having a $\Delta \mathrm{H}^{\circ}$ of $80-450 \mathrm{~kJ} / \mathrm{mol}^{81-83}$. The adsorption spontaneity was inferred from the negative $\Delta G^{\circ}$ values for both pollutants on WTA and $\mathrm{ATC}^{84}$; this finding was supported by the negative $\Delta \mathrm{S}^{\circ}$ values $^{85}$. Also, the adsorption appeared to go less spontaneous as the temperature increased. Nevertheless, the obtained $\Delta \mathrm{G}^{\mathrm{o}}$ values (less than $20 \mathrm{~kJ} \mathrm{~mol}^{-1}$ ) indicated that the adsorption process is a physisorption ${ }^{67,68,83,86-88}$.

Application to natural water samples. Tap water (TW) was collected from the chemistry Lab at Riyadh, Kingdom of Saudi Arabia (KSA). The Red Sea water sample (RSW) was picked from the coast of Jeddah CityKSA, while the groundwater (GW) sample was collected from the Sudair area (150 km North Riyadh-KSA). All samples were collected during the summer season, the total dissolved salts for TW, GW, and RSW was 0.2, 1.1 and $32.5 \mathrm{~g} \mathrm{~L}^{-1}$, respectively; and the total hardness was $146.2,751.8$ and $7293 \mathrm{mg} \mathrm{L}^{-1}$, respectively. The applicability of WTC and ATC for the removal of MF and PA from TW, GW, and RSW was explored. A concentration of 1,5 , and $10 \mathrm{mg} \mathrm{L}^{-1}$ were prepared for each drug in $250 \mathrm{~mL}$ of each water sample. The optimized conditions were applied, and the removal of PA and MF by WTC and ATC (S. 3). WTC and ATC were found to be efficient for the removal of PA and MF from the three samples. Besides, a promising result has emerged during this application that the total dissolved solids (TDS) of RSW, which was measured by a conductivity-meter (Jennway 6605), decreased significantly after being in contact with the sorbents revealing a desalination capacity of 1200 and $1500 \mathrm{mg} \mathrm{g}^{-1}$ for WTC and ATC, respectively.

\section{Conclusion}

This work demonstrates the optimization of adsorption of PA and MF by WTC and ATC from aqueous solution. The optimized conditions were applied to real environmental water samples. The adsorption isotherms data fitted the Freundlich model, and the adsorption processes obeyed the pseudo-second-order with a better regression parameter with the NLPSO. The maximum adsorption capacity ranged between 20.4 and $30.5 \mathrm{mg} \mathrm{g}^{-1}$. The application of both sorbents for fast removal of PA and MF from contaminated water is recommended. Considering the almost-zero-cost sorbent, the relatively short intake time and the desalination effect.

\section{Experimental}

Materials. NC was collected from the Eldoushain area, Nile River state, Sudan, hydrochloric acid $37 \%$ was purchased from Sharlau-Spain. The active pharmaceutical ingredients MF and PA were purchased from Ranbaxy Laboratories Limited, India. The washing of sorbent and the preparation of all solutions were performed using distilled water.

Preparation of WTC and ATC. The NC was crushed in a porcelain mortar and milled by ball milling at $500 \mathrm{rpm}$ for $30 \mathrm{~min}$, the ball: clay mass was 1:1. $10 \mathrm{~g}$ of NC were stirred with $200 \mathrm{~mL}$ distilled water for $1 \mathrm{~h}$, filtered through Buchner system, washed by $1 \mathrm{~L}$ distilled water, dried at $120^{\circ} \mathrm{C}$ for $2 \mathrm{~h}$, cooled in a desiccator, and kept in a polypropylene container. $10 \mathrm{~g}$ of NC were stirred with $200 \mathrm{~mL}$ of diluted hydrochloric acid (1:1), filtered through Buchner system, washed by distilled water (to $\mathrm{pH}=7$ ), dried at $120^{\circ} \mathrm{C}$ for $2 \mathrm{~h}$, cooled in a desiccator, and kept in a polypropylene container.

Characterization of WTC and ATC. WTC and ATC were characterized using scanning electron-energy dispersive X-ray technique (SEM-EDS), model JSM-IT300. The WTC and ATC crystalline structures were examined by X-Ray diffractometer, Bruker, D8 Advance; Billerica, MA, USA. The functional groups for both sorbents were monitored using Bruker TENSOR-FTIR spectrophotometer (Germany). Characteristics of pores (i.e., pore diameter and volume) and specific Brunauer-Emmett-Teller (BET) surface area were evaluated based on $\mathrm{N}_{2}$ adsorption-desorption isotherms at $77 \mathrm{~K}$ using an ASAP 2020 Micromeritics analyzer. The surface area, pore size and pore diameter were calculated from the Brunauer-Emmett-Teller (BET) equation ${ }^{89}$.

Adsorption experiments. Both PA and MF were analyzed by UV-Vis spectrophotometer (D3500 LABOMED) at $234 \mathrm{~nm}$ and $245 \mathrm{~nm}$, respectively. The adsorption parameters were optimized, including the impacts of the initial fed concentration (1-20 mg L $\mathrm{L}^{-1}$ ), sorbate-sorbent contact time, solution $\mathrm{pH}(1.0-10.0)$, and solution temperature (298-318 K). Also, the impact of ionic strength on the adsorption process was conducted by performing preparing pollutants solutions in sodium chloride solution $(0.01-0.1 \mathrm{M})$. For the contact time 

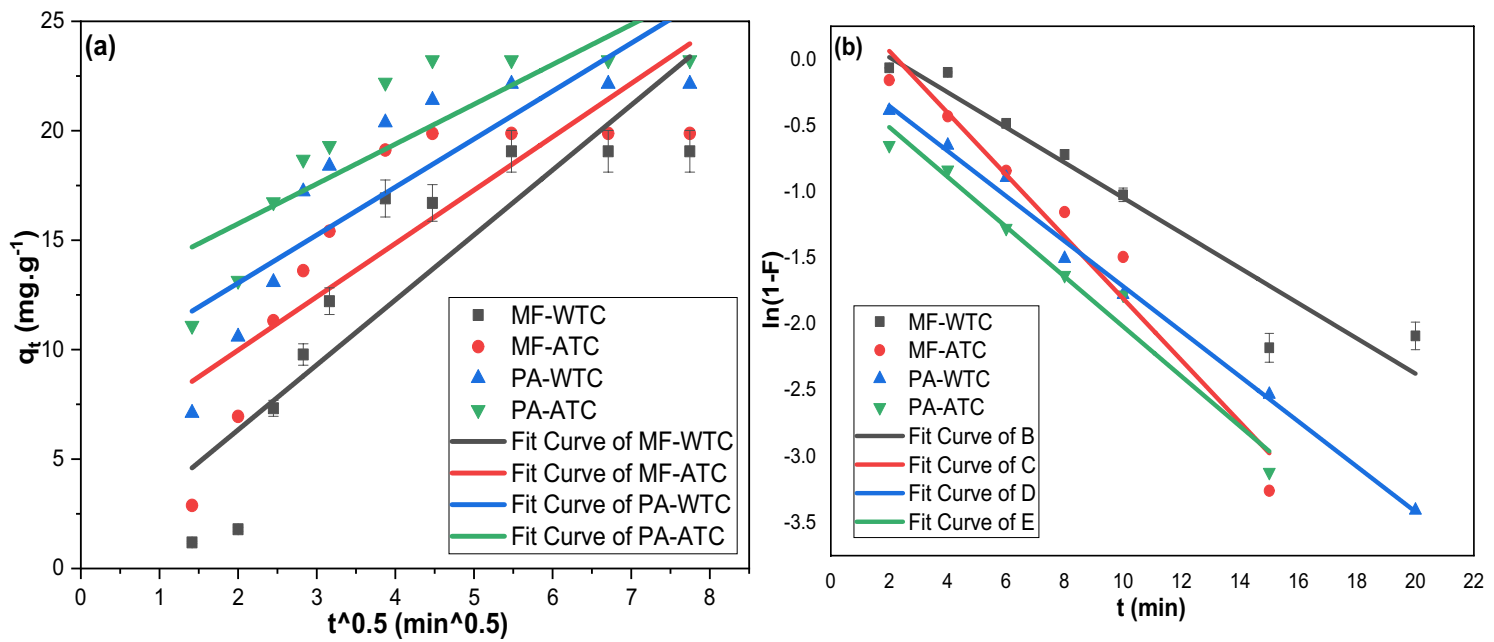

Figure 4. (a) IPDM, and (b) LFDM fittings for the adsorption of MF and PA on WTC and ATC.
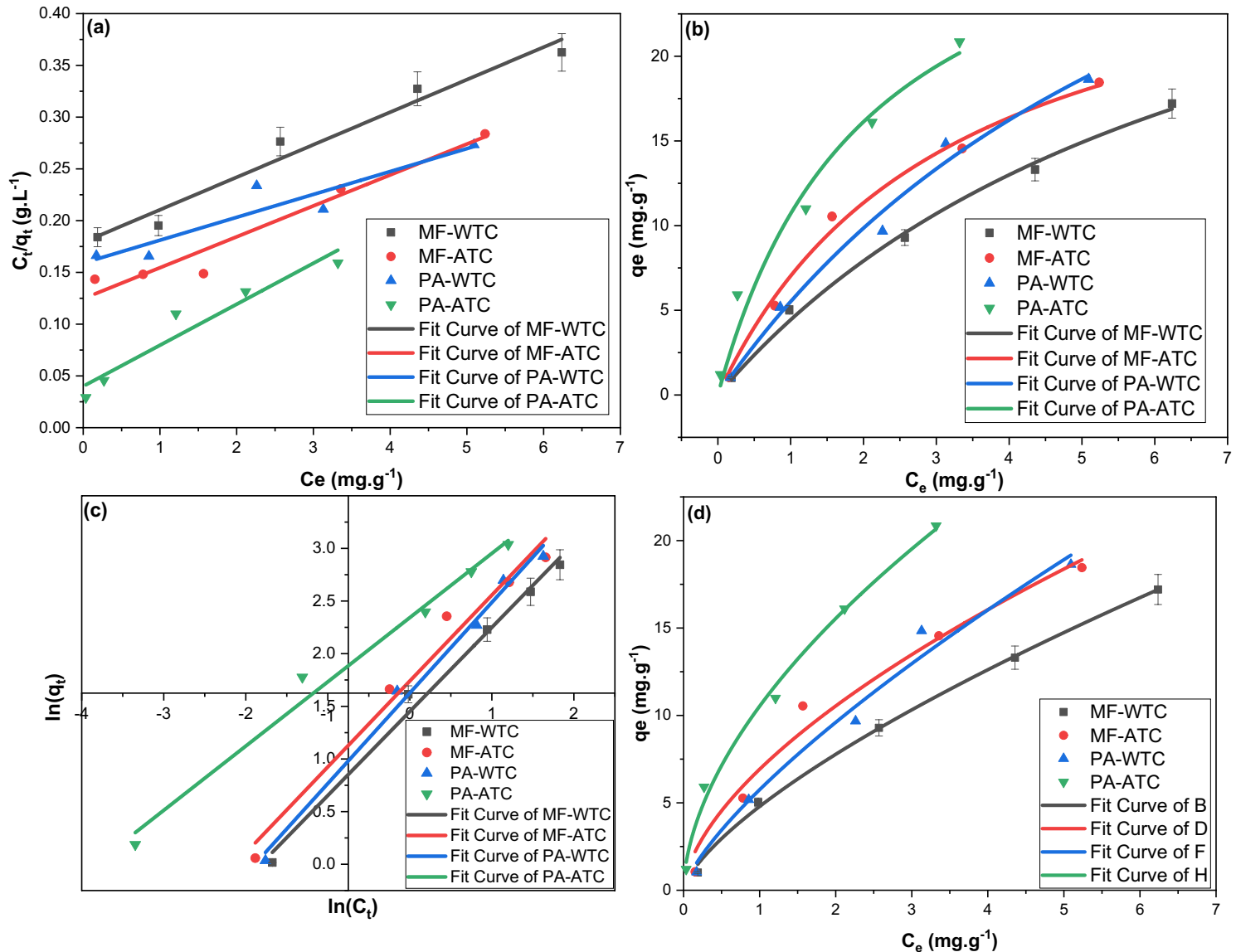

Figure 5. (a) LLM, (b) NLLM, (c) LFM and (d) NLFM for the adsorption of PA and MF on WTC and ATC. 

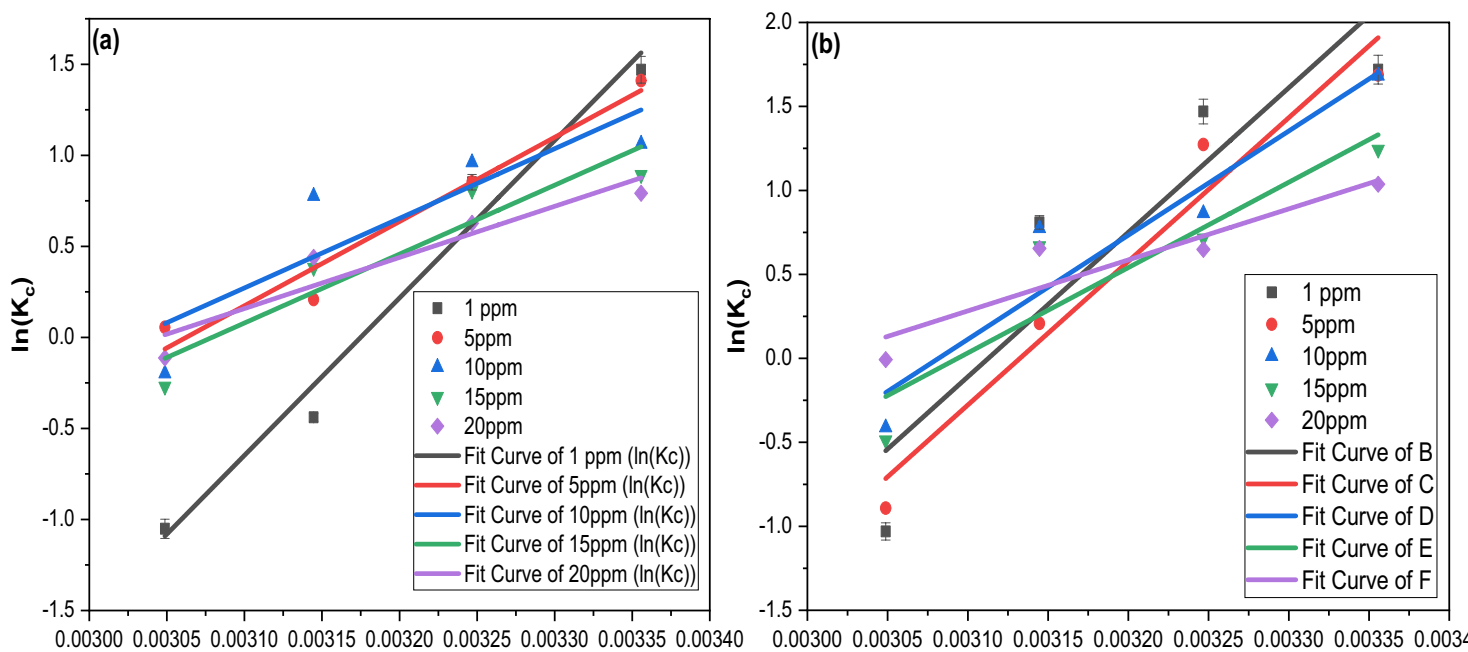

$1 / \mathrm{T}\left(\mathrm{K}^{-1}\right)$
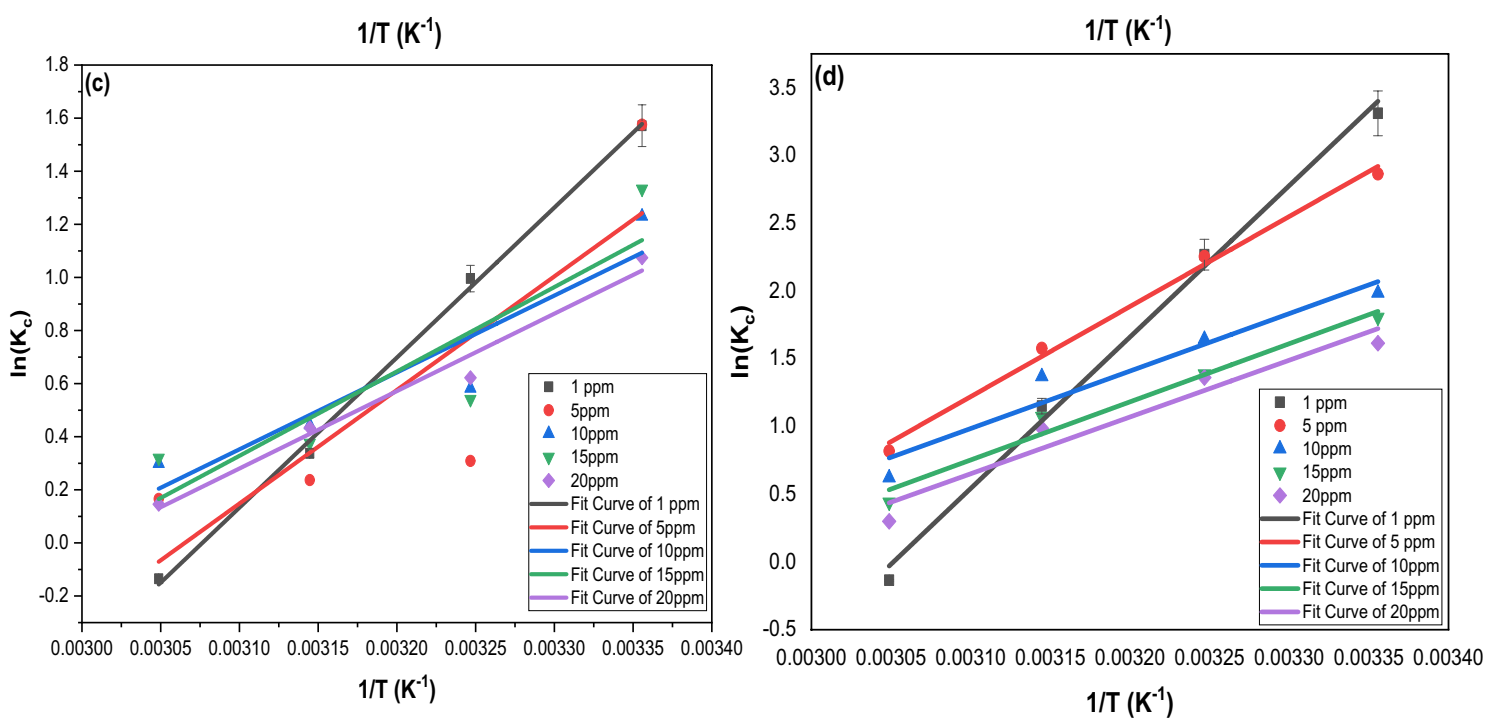

Figure 6. The plot of $\ln K_{\mathrm{c}}$ against $1 / T$ for the adsorption of different initial feed concentrations of (a) MF on WTC, (b) MF on ATC, (c) MF on WTC, and (d) MF on ATC.

study, $20.0 \mathrm{mg} \mathrm{L}^{-1}$ solution of each drug was prepared in distilled water with the aid of sonication. $80 \mathrm{mg}$ of each sorbent was stirred with $200 \mathrm{~mL}$ of each solution, and $5 \mathrm{~mL}$ of each mixture was taken during the time; each solution was then filtered by a nylon syringe filter $(0.22 \mu \mathrm{m})$ and subjected to UV-Vis analysis. The percentage of adsorption and adsorption capacity were calculated by Eqs. (14) and (15).

$$
\begin{gathered}
\text { Adsorption percentage }=\frac{\left(C_{o}-C_{t}\right)}{C_{o}} \times 100 \% \\
q_{t}=\frac{\left(C_{o}-C_{t}\right) V}{M},
\end{gathered}
$$

where $C_{o}$ is the initial fed concentration, $C_{t}$ is the unabsorbed concentration, $q_{t}$ is the adsorbed amount $\left(\mathrm{mg} \mathrm{g}^{-1}\right)$, $\mathrm{V}$ is the volume of the solution $(\mathrm{L})$, and $\mathrm{M}$ is the mass of sorbent $(\mathrm{g})$. Each experiment was carried three times, and the average was calculated. 


\begin{tabular}{|c|c|c|c|c|c|c|}
\hline $\begin{array}{l}\text { Fed conc } \\
\left(\mathrm{mg} \mathrm{L}^{-} \mathbf{1}\right)\end{array}$ & $\begin{array}{l}\Delta \mathrm{H}^{\mathrm{o}} \\
\left(\mathrm{kJ} \mathrm{mol}^{-1}\right)\end{array}$ & $\begin{array}{l}\Delta S^{o} \\
\left(\mathrm{~kJ} \mathrm{~mol}^{-1}\right)\end{array}$ & 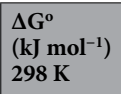 & 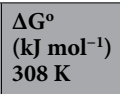 & 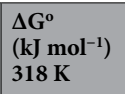 & 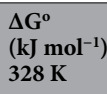 \\
\hline \multicolumn{7}{|c|}{ Thermodynamic parameters } \\
\hline \multicolumn{7}{|c|}{ MF-WTC } \\
\hline 1 & -71.902 & -0.228 & -3.873 & -1.591 & 0.692 & 2.975 \\
\hline 5 & -38.462 & -0.118 & -3.361 & -2.183 & -1.006 & 0.172 \\
\hline 10 & -31.795 & -0.096 & -3.096 & -2.133 & -1.170 & -0.207 \\
\hline 15 & -31.477 & -0.097 & -2.594 & -1.625 & -0.656 & 0.313 \\
\hline 20 & -23.351 & -0.071 & -2.171 & -1.461 & -0.750 & -0.039 \\
\hline \multicolumn{7}{|l|}{ MF-ATC } \\
\hline 1 & -71.532 & -0.223 & -5.179 & -2.953 & -0.726 & 1.501 \\
\hline 5 & -71.110 & -0.223 & -4.731 & -2.504 & -0.276 & 1.951 \\
\hline 10 & -51.562 & -0.159 & -4.210 & -2.621 & -1.032 & 0.557 \\
\hline 15 & -42.236 & -0.131 & -3.299 & -1.992 & -0.686 & 0.621 \\
\hline 20 & -25.248 & -0.076 & -2.624 & -1.865 & -1.106 & -0.346 \\
\hline \multicolumn{7}{|l|}{ PA-ATC } \\
\hline 1 & -46.981 & -0.145 & -3.910 & -2.464 & -1.019 & 0.426 \\
\hline 5 & -35.564 & -0.109 & -3.078 & -1.988 & -0.897 & 0.193 \\
\hline 10 & -24.079 & -0.072 & -2.708 & -1.991 & -1.274 & -0.557 \\
\hline 15 & -26.420 & -0.079 & -2.826 & -2.034 & -1.243 & -0.451 \\
\hline 20 & -24.243 & -0.073 & -2.542 & -1.814 & -1.086 & -0.357 \\
\hline \multicolumn{7}{|l|}{ PA-WTC } \\
\hline 1 & -92.922 & -0.284 & -8.424 & -5.589 & -2.753 & 0.082 \\
\hline 5 & -55.273 & -0.161 & -7.235 & -5.623 & -4.011 & -2.399 \\
\hline 10 & -35.263 & -0.101 & -5.127 & -4.116 & -3.104 & -2.093 \\
\hline 15 & -35.675 & -0.104 & -4.583 & -3.540 & -2.497 & -1.453 \\
\hline 20 & -34.836 & -0.103 & -4.267 & -3.241 & -2.216 & -1.190 \\
\hline
\end{tabular}

Table 2. Thermodynamic parameters for the adsorption of MF and PA on WTC and ATC at a temperature range of $298-328^{\circ} \mathrm{K}$.

Received: 9 November 2020; Accepted: 21 June 2021

Published online: 30 June 2021

\section{References}

1. Cabrera-Lafaurie, W. A., Román, F. R. \& Hernández-Maldonado, A. J. Transition metal modified and partially calcined inorganicorganic pillared clays for the adsorption of salicylic acid, clofibric acid, carbamazepine, and caffeine from water. J. Colloid Interface Sci. 386, 381-391 (2012).

2. Yang, Y., Ok, Y. S., Kim, K.-H., Kwon, E. E. \& Tsang, Y. F. Occurrences and removal of pharmaceuticals and personal care products (PPCPs) in drinking water and water/sewage treatment plants: A review. Sci. Total Environ. 596, 303-320 (2017).

3. Ruhoy, I. S. \& Daughton, C. G. Beyond the medicine cabinet: An analysis of where and why medications accumulate. Environ. Int. 34(8), 1157-69 (2008).

4. Zhao, Y. \& Xiao, X. in Emerging Chemicals and Human Health 165-178 (Springer, 2019).

5. Gupta, R., Sati, B. \& Gupta, A. in Advances in Biological Treatment of Industrial Waste Water and their Recycling for a Sustainable Future 267-302 (Springer, 2019).

6. Boyd, G. R., Reemtsma, H., Grimm, D. A. \& Mitra, S. Pharmaceuticals and personal care products (PPCPs) in surface and treated waters of Louisiana, USA and Ontario, Canada. Sci. Total Environ. 311, 135-149 (2003).

7. Rajapaksha, A. U., Premarathna, K. S. D., Gunarathne, V., Ahmed, A. \& Vithanage, M. in Pharmaceuticals and Personal Care Products: Waste Management and Treatment Technology 213-238 (Elsevier, 2019).

8. Seo, P. W., Bhadra, B. N., Ahmed, I., Khan, N. A. \& Jhung, S. H. Adsorptive removal of pharmaceuticals and personal care products from water with functionalized metal-organic frameworks: remarkable adsorbents with hydrogen-bonding abilities. Sci. Rep. 6, 34462 (2016).

9. Lima, E. C. Removal of emerging contaminants from the environment by adsorption. Ecotoxicol. Environ. Saf. 150, 1-17 (2018).

10. Xu, Y. et al. Advances in technologies for pharmaceuticals and personal care products removal. J. Mater. Chem. A 5, 12001-12014 (2017).

11. Pandiarajan, A., Kamaraj, R. \& Vasudevan, S. Enhanced removal of cephalosporin based antibiotics (CBA) from water by one-pot electrosynthesized $\mathrm{Mg}(\mathrm{OH}) 2$ : a combined theoretical and experimental study to pilot scale. New J. Chem. 41(11), 4518-30 (2017).

12. Adeleye, A. S. et al. Engineered nanomaterials for water treatment and remediation: costs, benefits, and applicability. Chem. Eng. J. 286, 640-662 (2016).

13. Pandiarajan, A., Kamaraj, R., Vasudevan, S. \& Vasudevan, S. OPAC (orange peel activated carbon) derived from waste orange peel for the adsorption of chlorophenoxyacetic acid herbicides from water: adsorption isotherm, kinetic modelling and thermodynamic studies. Bioresour. Technol. 261, 329-41 (2018).

14. Kamaraj, R. \& Vasudevan, S. Decontamination of selenate from aqueous solution by oxidized multi-walled carbon nanotubes. Powder Technol. 274, 268-75 (2015). 
15. Ganesan, P., Kamaraj, R. \& Vasudevan, S. Application of isotherm, kinetic and thermodynamic models for the adsorption of nitrate ions on graphene from aqueous solution. J. Taiwan Inst. Chem. Eng. 44(5), 808-14 (2013).

16. Lakshmi, J. \& Vasudevan, S. Graphene-A promising material for removal of perchlorate $\left(\mathrm{ClO}_{4}^{-}\right)$from water. Environ. Sci. Pollut. Res. 20(8), 5114-24 (2013).

17. Ganesan, P., Kamaraj, R., Sozhan, G. \& Vasudevan, S. Oxidized multiwalled carbon nanotubes as adsorbent for the removal of manganese from aqueous solution. Environ. Sci. Pollut. Res. 20(2), 987-96 (2013).

18. Sun, Y. et al. Retracted Article: Enhanced adsorption of ionizable aromatic compounds on humic acid-coated carbonaceous adsorbents. RSC Adv. 2(27), 10359-64 (2012).

19. Kamaraj, R., Aravind, P. \& Vasudevan, S. Nitrogen doped graphene nano sheets (N-Gns) as electrocatalyst for electro-fenton process for the degradation of highly toxic chlorophenoxy acid herbicides from water. Chem. Select. 6(11), 2804-10 (2021).

20. Elamin, M. R., Abdulkhair, B. Y. \& Elzupir, A. O. Insight to aspirin sorption behavior on carbon nanotubes from aqueous solution: Thermodynamics, kinetics, influence of functionalization and solution parameters. Sci. Rep. 9(1), 1 (2019).

21. Chiappone, A., Marello, S., Scavia, C. \& Setti, M. Clay mineral characterization through the methylene blue test: comparison with other experimental techniques and applications of the method. Can. Geotech. J. 41, 1168-1178 (2004).

22. Dessalew, D., Alemayehu, S., Singh, K. \& Dejene, T. Assessment of the adsorption capacities of fired clay soils from Jimma (Ethiopia) for the removal of Cr (VI) from aqueous solution. Univ. J. Environ. Res. Technol. 2, 411-20 (2012).

23. Styszko, K., Nosek, K., Motak, M. \& Bester, K. Preliminary selection of clay minerals for the removal of pharmaceuticals, bisphenol A and triclosan in acidic and neutral aqueous solutions. C. R. Chim. 18, 1134-1142 (2015).

24. Liu, Y., Lu, X., Wu, F. \& Deng, N. Adsorption and photooxidation of pharmaceuticals and personal care products on clay minerals. React. Kinet. Mech. Catal. 104, 61-73 (2011).

25. Sun, K., Shi, Y., Chen, H., Wang, X. \& Li, Z. Extending surfactant-modified 2: 1 clay minerals for the uptake and removal of diclofenac from water. J. Hazard. Mater. 323, 567-574 (2017).

26. Uddin, M. K. A review on the adsorption of heavy metals by clay minerals, with special focus on the past decade. Chem. Eng. J. 308, 438-462 (2017)

27. Djebbar, M., Djafri, F., Bouchekara, M. \& Djafri, A. Adsorption of phenol on natural clay. Appl. Water Sci. 2, 77-86 (2012).

28. Peng, N. et al. Superabsorbent cellulose-clay nanocomposite hydrogels for highly efficient removal of dye in water. ACS Sustain. Chem. Eng. 4, 7217-7224 (2016).

29. Lozano-Morales, V., Gardi, I., Nir, S. \& Undabeytia, T. Removal of pharmaceuticals from water by clay-cationic starch sorbents. J. Clean. Prod. 190, 703-711 (2018).

30. Scheurer, M., Michel, A., Brauch, H.-J., Ruck, W. \& Sacher, F. Occurrence and fate of the antidiabetic drug metformin and its metabolite guanylurea in the environment and during drinking water treatment. Water Res. 46, 4790-4802 (2012).

31. Briones, R. M., Sarmah, A. K. \& Padhye, L. P. A global perspective on the use, occurrence, fate and effects of anti-diabetic drug metformin in natural and engineered ecosystems. Environ. Pollut. 219, 1007-1020 (2016).

32. Tisler, S. \& Zwiener, C. Formation and occurrence of transformation products of metformin in wastewater and surface water. Sci. Total Environ. 628, 1121-1129 (2018).

33. Zhang, P. et al. Occurrence of pharmaceuticals and personal care products, and their associated environmental risks in a large shallow lake in north China. Environ. Geochem. Health 40(4), 1525-39 (2018).

34. Ali, A. M., Rønning, H. T., Alarif, W., Kallenborn, R. \& Al-Lihaibi, S. S. Occurrence of pharmaceuticals and personal care products in effluent-dominated Saudi Arabian coastal waters of the Red Sea. Chemosphere 175, 505-13 (2017).

35. Bertolini, A. et al. Paracetamol: new vistas of an old drug. CNS Drug Rev. 12(3-4), 250-75 (2006).

36. Klotz, U. Paracetamol (acetaminophen) - a popular and widely used nonopioid analgesic. Arzneimittelforschung 62(08), 355-9 (2012).

37. Torjesen, I. (British Medical Journal Publishing Group, 2020).

38. Lechien, J. R. et al. Olfactory and gustatory dysfunctions as a clinical presentation of mild-to-moderate forms of the coronavirus disease (COVID-19): A multicenter European study. Eur. Arch. Oto-Rhino-Laryngol. 277(8), 2251-61 (2020).

39. Estébanez, A. et al. Cutaneous manifestations in COVID-19: a new contribution. J. Eur. Acad. Dermatol. Venereol. 34(6), e250-e251 (2020).

40. Dontsova, T. A. et al. Directional control of the structural adsorption properties of clays by magnetite modification. J. Nanomater. https://doi.org/10.1155/2018/6573016 (2018).

41. Vezentsev, A. I., Kormosh, E. V., Peristaya, L. F., Shamshurov, A. V. \& Cherkasov, R. A. Material composition and colloid-chemical properties of natural and modified montmorillonite clays. ARPN J. Eng. Appl. Sci. 9(11), 2358-2366 (2014).

42. Ehsan, A., Bhatti, H. N., Iqbal, M., Noreen, S. J. W. S. \& Technology, ,. Native, acidic pre-treated and composite clay efficiency for the adsorption of dicationic dye in aqueous medium. Water Sci. Technol. 75, 753-764 (2017).

43. Myasnikov, S., Tikhonov, A. Y., Chipryakova, A. \& Kulov, N. Removal of heavy metal ions from water by an combined sorptioncrystallization process using activated clays. Theor. Found. Chem. Eng. 50, 366-382 (2016).

44. Batool, F. et al. Study of isothermal, kinetic, and thermodynamic parameters for adsorption of cadmium: an overview of linear and nonlinear approach and error analysis . Bioorg. Chem. Appl. https://doi.org/10.1155/2018/3463724 (2018).

45. Moussout, H., Ahlafi, H., Aazza, M. \& Maghat, H. Critical of linear and nonlinear equations of pseudo-first order and pseudosecond order kinetic models. Karbala Int. J. Mod. Sci. 4(2), 244-54 (2018).

46. Xiao, Y., Azaiez, J. \& Hill, J. M. Erroneous application of pseudo-second-order adsorption kinetics model: ignored assumptions and spurious correlations. Ind. Eng. Chem. Res. 57(7), 2705-9 (2018).

47. Mallakpour, S. \& Rashidimoghadam, S. Poly (vinyl alcohol)/Vitamin C-multi walled carbon nanotubes composites and their applications for removal of methylene blue: Advanced comparison between linear and nonlinear forms of adsorption isotherms and kinetics models. Polymer 160, 115-25 (2019).

48. Kausar, A. et al. Preparation and characterization of chitosan/clay composite for direct Rose FRN dye removal from aqueous media: comparison of linear and non-linear regression methods. J. Mater. Res. Technol. 8(1), 1161-74 (2019).

49. Wang, N., Han, Y. \& Li, S. Adsorption characteristic of $\mathrm{Cr}$ (VI) onto different activated coal fly ashes: kinetics, thermodynamic, application feasibility, and error analysis. Water Air Soil Pollut. 230(7), 1-3 (2019).

50. Michen, B., Diatta, A., Fritsch, J., Aneziris, C. \& Graule, T. Removal of colloidal particles in ceramic depth filters based on diatomaceous earth. Sep. Purif. Technol. 81, 77-87 (2011).

51. Cai, L. et al. Facile preparation of nano-Bi2MoO6/diatomite composite for enhancing photocatalytic performance under visible light irradiation. Materials 11, 267 (2018).

52. Bouchmila, I., Kefi, B. B., Souissi, R. \& Abdellaoui, M. Purification, characterization and application of cherty rocks as sorbent for separation and preconcentration of rare earths. J. Market. Res. 8, 2910-2923 (2019).

53. Rouquerol, J., Rouquerol, F., Llewellyn, P., Maurin, G. \& Sing, K. S. Adsorption by powders and porous solids: principles, methodology and applications. (Academic Press, 2013).

54. Abduljauwad, S. N. Enhancing cancer cell adhesion with clay nanoparticles for countering metastasis. Sci. Rep. 9, 5935 (2019).

55. García-Guzmán, P. et al. Rheological mucoadhesion and cytotoxicity of montmorillonite clay mineral/hybrid microparticles biocomposite. Appl. Clay Sci. 180, 105202 (2019).

56. Hu, F. et al. Effect of soil particle interaction forces in a clay-rich soil on aggregate breakdown and particle aggregation. Eur. J. Soil Sci. 70, 268-277 (2019). 
57. Alnajjar, M. et al. Silica-alumina composite as an effective adsorbent for the removal of metformin from water. J. Environ. Chem. Eng. 7, 102994 (2019).

58. Zhu, S. et al. Adsorption of emerging contaminant metformin using graphene oxide. Chemosphere 179, 20-8 (2017).

59. Rebitski, E. P., Aranda, P., Darder, M., Carraro, R. \& Ruiz-Hitzky, E. Intercalation of metformin into montmorillonite. Dalton Trans. 47(9), 3185-92 (2018).

60. Kyzas, G. Z. et al. Effectively designed molecularly imprinted polymers for selective isolation of the antidiabetic drug metformin and its transformation product guanylurea from aqueous media. Anal. Chim. Acta 866, 27-40 (2015).

61. Chauhan, M., Saini, V. K. \& Suthar, S. Enhancement in selective adsorption and removal efficiency of natural clay by intercalation of Zr-pillars into its layered nanostructure. J. Clean. Prod. 258, 120686 (2020).

62. Anirudhan, T. S., Gopal, S. S. \& Sandeep, S. Synthesis and characterization of montmorillonite/N-(carboxyacyl) chitosan coated magnetic particle nanocomposites for controlled delivery of paracetamol. Appl. Clay Sci. 88, 151-8 (2014).

63. Sumalinog, D. A., Capareda, S. C. \& de Luna, M. D. Evaluation of the effectiveness and mechanisms of acetaminophen and methylene blue dye adsorption on activated biochar derived from municipal solid wastes. J. Environ Manag. 210, 255-62 (2018).

64. Zhang, J. Z. \& Huang, X. L. Effect of temperature and salinity on phosphate sorption on marine sediments. Environ. Sci. Technol. 45(16), 6831-7 (2011).

65. Flower, H. et al. Saltwater intrusion as potential driver of phosphorus release from limestone bedrock in a coastal aquifer. Estuarine Coast. Shelf Sci. 184, 166-76 (2017).

66. Zhang, J. Z. Avoiding spurious correlation in analysis of chemical kinetic data. Chem. Commun. 47(24), 6861-3 (2011).

67. Acharya, J., Sahu, J., Mohanty, C. \& Meikap, B. Removal of lead (II) from wastewater by activated carbon developed from Tamarind wood by zinc chloride activation. Chem. Eng. J. 149, 249-262 (2009).

68. Mallakpour, S. \& Tabesh, F. Tragacanth gum based hydrogel nanocomposites for the adsorption of methylene blue: Comparison of linear and non-linear forms of different adsorption isotherm and kinetics models. Int. J. Biolog. Macromol. 133, 754-66 (2019).

69. El-Khaiary, M. I., Malash, G. F. \& Ho, Y. S. On the use of linearized pseudo-second-order kinetic equations for modeling adsorption systems. Desalination 257(1-3), 93-101 (2010).

70. Naghizadeh, A., Karimi, A., Derakhshani, E. \& Esform, A. J. E. Q. M. Single-walled carbon nanotubes (SWCNTs) as an efficient adsorbent for removal of reactive dyes from water solution: Equilibrium, kinetic, and thermodynamic. Environ. Quality Manag. https://doi.org/10.1002/tqem.21753 (2021).

71. Elamin, M. R., Abdulkhair, B. Y. \& Elzupir, A. O. Insight to aspirin sorption behavior on carbon nanotubes from aqueous solution: Thermodynamics, kinetics, influence of functionalization and solution parameters. Sci. Rep. 9, 1-10 (2019).

72. Debnath, S. \& Ghosh, U. C. Equilibrium modeling of single and binary adsorption of Cd (II) and Cu (II) onto agglomerated nano structured Titanium(IV) oxide. Desalination 273(2-3), 330-42 (2011).

73. Shukla, S. P. \& Kisku, G. C. Linear and non-linear kinetic modeling for adsorption of disperse dye in batch process. Res. J. Environ. Toxicol. 9(6), 320 (2015).

74. Hameed, B., Krishni, R. R. \& Sata, S. A. A novel agricultural waste adsorbent for the removal of cationic dye from aqueous solutions. J. Hazard. Mater. 162(1), 305-11 (2009).

75. Vasudevan, S., Lakshmi, J. \& Sozhan, G. Optimization of the process parameters for the removal of phosphate from drinking water by electrocoagulation. Desalin. Water Treat. 12(1-3), 407-14 (2009).

76. Nanta, P., Kasemwong, K. \& Skolpap, W. Isotherm and kinetic modeling on superparamagnetic nanoparticles adsorption of polysaccharide. J. Environ. Chem. Eng. 6(1), 794-802 (2018).

77. Kumar, P. S. et al. Adsorption of dye from aqueous solution by cashew nut shell: Studies on equilibrium isotherm, kinetics and thermodynamics of interactions. Desalination 261(1-2), 52-60 (2010).

78. Aljeboree, A. M., Alshirifi, A. N. \& Alkaim, A. F. Kinetics and equilibrium study for the adsorption of textile dyes on coconut shell activated carbon. Arab. J. Chem. 10, S3381-93 (2017).

79. Jain, S. N. et al. Nonlinear regression approach for acid dye remediation using activated adsorbent: Kinetic, isotherm, thermodynamic and reusability studies. Microchem. J. 148, 605-15 (2019).

80. Do, D. D. Adsorption analysis: Equilibria and kinetics. Vol. 2 (Imperial College Press, London, 1998).

81. Letshwenyo, M. W. \& Mokgosi, S. Investigation of water treatment sludge from drinking water treated with Zetafloc 553I coagulant for phosphorus removal from wastewater. J. Environ. Manag. 282, 111909 (2021).

82. Demirbas, O. et al. Equilibrium, kinetics, and thermodynamic of adsorption of enzymes on diatomite clay materials. BioNanoScience 9(2), 474-82 (2019).

83. Aarab, N. et al. Removal of an emerging pharmaceutical pollutant (metronidazole) using PPY-PANi copolymer: kinetics, equilibrium and DFT identification of adsorption mechanism. Groundwater Sustain Dev. 11, 100416 (2020).

84. Vasudevan, S. \& Lakshmi, J. Studies relating to an electrochemically assisted coagulation for the removal of chromium from water using zinc anode. Water Sci. Technol. Water Supply 11(2), 142-50 (2011).

85. Acharya, J., Sahu, J. N., Mohanty, C. R. \& Meikap, B. C. Removal of lead (II) from wastewater by activated carbon developed from Tamarind wood by zinc chloride activation. Chem. Eng. J. 149(1-3), 249-62 (2009).

86. El-Bindary, A. A., El-Sonbati, A. Z., Al-Sarawy, A. A., Mohamed, K. S. \& Farid, M. A. Adsorption and thermodynamic studies of hazardous azocoumarin dye from an aqueous solution onto low cost rice straw based carbons. J. Mol. Liq. 199, 71-8 (2014).

87. Melo, B. C. et al. Cellulose nanowhiskers improve the methylene blue adsorption capacity of chitosan- $g$-poly (acrylic acid) hydrogel. Carbohydr. Polym. 181, 358-67 (2018).

88. Abukhadra, M. R., Adlii, A., El-Sherbeeny, A. M., Soliman, A. T. \& Abd, E. E. Promoting the decontamination of different types of water pollutants $\left(\mathrm{Cd}^{2+}\right.$, safranin dye, and phosphate) using a novel structure of exfoliated bentonite admixed with cellulose nanofiber. J. Environ. Manag. 273, 111130 (2020).

89. Lippens, B. \& De Boer, J. Pore systems in catalysts V. The t-method. J. Catal. 4, 319-323 (1965).

\section{Author contributions}

M.R.E., B.Y.A., F.K.A. and L.K. all together participated in the practical part. B.Y.A. have performed the calculation and graphing work. M.R.E. and B.Y.A. prepared the first draft for this manuscript. F.K.A. and L.K. finalized this manuscript. B.Y.A. revised this manuscript.

\section{Competing interests}

The authors declare no competing interests.

\section{Additional information}

Supplementary Information The online version contains supplementary material available at https://doi.org/ 10.1038/s41598-021-93040-y.

Correspondence and requests for materials should be addressed to B.Y.A. 
Reprints and permissions information is available at www.nature.com/reprints.

Publisher's note Springer Nature remains neutral with regard to jurisdictional claims in published maps and institutional affiliations.

(c) (i) Open Access This article is licensed under a Creative Commons Attribution 4.0 International License, which permits use, sharing, adaptation, distribution and reproduction in any medium or format, as long as you give appropriate credit to the original author(s) and the source, provide a link to the Creative Commons licence, and indicate if changes were made. The images or other third party material in this article are included in the article's Creative Commons licence, unless indicated otherwise in a credit line to the material. If material is not included in the article's Creative Commons licence and your intended use is not permitted by statutory regulation or exceeds the permitted use, you will need to obtain permission directly from the copyright holder. To view a copy of this licence, visit http://creativecommons.org/licenses/by/4.0/.

(C) The Author(s) 2021 